\title{
DIÁLOGO E CONCERTAÇÃO: ESTRATÉGIA PARA REPENSAR A UNIVERSIDADE ESTADUAL DO RIO GRANDE DO SUL
}

\author{
Luciano Andreatta-da-Costa ${ }^{1}$, J. D. Vieira ${ }^{2}$ \\ ${ }^{1}$ Universidade Estadual do Rio Grande do Sul, Unidade de Porto Alegre, Avenida Bento Gonçalves, 8855 - Agronomia, CEP 91540-000, Porto \\ Alegre, RS. E-mail: luciano@uergs.edu.br \\ ${ }^{2}$ Doutora em Políticas Públicas e Gestão da Educação Básica pela Universidade de Brasília, Porto Alegre, RS.
}

\begin{abstract}
Resumo - Este artigo apresenta um movimento dialógico e dialético entre governo, universidades e outros atores sociais, que visava a criação de soluções para a Universidade do Estado do Rio Grande do Sul. O estudo parte do relatório das atividades de um grupo de trabalho - GT, destinado para esta finalidade. $O$ artigo identifica a possibilidade de diálogo e consulta como uma forma de elaboração de políticas públicas, apesar dos papéis sociais distintos de pessoas envolvidas no processo. Os autores tiveram participação direta no processo, de modo que suas percepções não são livres de motivação nem crença anterior nos resultados do trabalho. Ambos atuavam como gestores no executivo estadual e foram designados para propor uma estratégia para a Uergs. Por outro lado esta circunstância motivou este registro, tornando-se esta experiência uma contribuição teórica e metodológica para o debate sobre o ensino superior público.
\end{abstract}

Palavras-chave - Educação Superior. Gestão Universitária. Política Públicas em Educação.

Abstract - This paper presents a dialogical and dialectical movement among government, university and other social actors, that was aimed at setting solutions for the State University of Rio Grande do Sul. The study starts on the report of the activities of a working group - GT, aimed for this purpose. The article identifies the feasibility of dialogue and consultation as a form of public policy making, despite the distinct social roles of those involved in the process. The authors had direct participation in the process, so their perceptions are not free of motivation nor prior belief in the results of work. Both act as managers in state government and were assigned to propose a strategy for UERGS. On the other hand this circumstance motived this record, becoming this experience a theoretical and methodological contribution to the debate on public higher education.

Keywords - Higher Education. University Management. Public Policies in Education.

Recebido em: 05 de dezembro de 2015. Aprovado em: 31 de dezembro de 2015.

\section{INTRODUÇÃ̃O}

A Universidade Estadual do Rio Grande do Sul (Uergs) nasce no ano de 2001 (RIO GRANDE DO SUL, 2001), em um contexto nacional de poucos investimentos nas Universidades Públicas, o que conferiu a esta criação um caráter contra-hegemônico, tendo em vista que a Educação Superior privada vinha atravessando uma significativa expansão, em detrimento das instituições públicas. De 1997 a 2002, houve uma redução no número de Instituições de Ensino Superior - IES públicas, passando de 211 para 195, diante de um crescimento de 764 para 1442 IES privadas (INSTITUTO NACIONAL DE ESTUDOS E PESQUISAS EDUCACIONAIS ANÍSIO TEIXEIRA, 2004). Ou seja, a participação das Públicas passou de quase $22 \%$ para menos de $12 \%$. Essa política concorreu para a elitização da educação superior no Brasil e, extensivamente, no Rio Grande do Sul. Por isso, a Uergs foi concebida, também, como uma forma de democratização do acesso da juventude à universidade. No período de 2002 a 2010, o número de IES públicas passou de 195 para 278, enquanto as privadas passaram de 1442 para 2100, mantendo-se a proporção existente (INSTITUTO NACIONAL DE ESTUDOS E PESQUISAS EDUCACIONAIS ANÍSIO TEIXEIRA, 2011). Esses números evidenciam o quanto a criação de uma universidade pública no ano de 2001 representava de fato uma ação até certo ponto de exceção, diferentemente do período posterior, que alterou essa tendência, mantendo, diante de expressivo aumento das IES públicas, a proporção das IES públicas e privadas.

Além disto, a proposta da universidade apresentou uma série de características que a diferenciavam das universidades públicas da época, por apresentar uma forte vinculação com as regiões, uma estrutura descentralizada e uma série de cursos com características novas e procurando uma vinculação com matriz produtiva de cada região. No texto de sua Lei de Criação (RIO GRANDE DO SUL, 2001), a universidade visa "ao desenvolvimento regional sustentável, ao aproveitamento de vocações e de estruturas culturais e produtivas locais". Outro aspecto inovador de sua criação está expresso no artigo 15 da Lei, que assegura $50 \%$ das vagas para os candidatos que comprovarem a condição de hipossuficiência econômica. Entre os cursos criados, se pode citar, por exemplo, os cursos de Engenharia em Energia e Engenharia de Bioprocessos e Biotecnologia, cursos até então praticamente inexistentes nas universidades brasileiras, mas que passaram a ser criados desde aquele período. Hoje existem 35 cursos de bacharelado 
ligados diretamente ao tema da Energia (BRASIL, 2015), sendo o da Uergs o primeiro a ser criado. Quanto ao curso de Engenharia de Bioprocessos e Biotecnologias, hoje existem 15 instituições ofertando, sendo que o da Uergs foi criado, só havia um curso nesta área (BRASIL, 2015).

No seu período inicial, a universidade contava com "um grupo de profissionais que tinha um perfil ligado à Educação Popular, aos Movimentos Sociais, ao processo transformador da Educação" (UNIVERSIDADE ESTADUAL DO RIO GRANDE DO SUL, 2012, p.5), características estas que também contribuíam para o ineditismo citado anteriormente. A partir daí a Universidade teve, além da sua reitoria pró-tempore inicial, mais duas indicadas pelos governos posteriores, o que contribuiu para restringir o projeto original da universidade. O exercício da Gestão Democrática da universidade ocorreu diante de forte mobilização, a partir da participação dos professores de cada região no Conselho Superior da Universidade (CONSUN) reivindicada pelo Sindicato representativo dos docentes, bem como da eleição dos Diretores Regionais em 2009 e da Reitoria em 2010. Somente no ano de 2011 os Diretores Regionais foram efetivamente reconhecidos pelo Governo do Estado, bem como a vice-Reitoria. Neste período iniciase um processo de resgate de sua origem, de reconhecimento de suas prerrogativas institucionais, de seu caráter regional, bem como de recuperação da capacidade infraestrutural, mediante aumento de aporte financeiro.

Neste contexto, este artigo descreve o trabalho realizado por um Grupo de Trabalho - GT nomeado pelo Governador do Estado do Rio Grande do Sul no ano de 2013, com a participação de representantes de professores, funcionários, Reitoria e Secretarias de Estado, cujos resultados foram submetidos ao Conselho Superior da Universidade e algumas ações daí decorrentes já foram materializas nos anos de 2013 e 2014. A descrição do trabalho do GT ocorrerá a luz desta evolução histórica da universidade, dos conceitos de Estado X Sociedade e dos desafios da universidade na Sociedade do Conhecimento, que serão descritos na seção seguinte.

Procurou-se investigar a adequação da metodologia de intervenção proposta, a qual levou em consideração diferentes setores da comunidade acadêmica e do poder executivo estadual, pretendendo-se, desta forma, obter a legitimidade suficiente para submeter a proposta aos Conselho Superior da Universidade - CONSUN. A partir da lógica da participação e da liberdade de expressão de todos os elementos do grupo, não houve a obrigatoriedade da existência de consensos. A condução do processo se deu a partir dos autores deste artigo, gestores do Governo do Estado no período, e que tiveram a atribuição de coordenar o grupo e levar a discussão ao CONSUN

2 ESTADO, SOCIEDADE E A UNIVERSIDADE NA SOCIEDADE DO CONHECIMENTO: A BUSCA DA QUALIDADE NA EDUCAÇÃO SUPERIOR

Nesta seção serão estabelecidos os elementos teóricos que darão subsídios às análises que serão feitas das propostas feitas à Uergs bem como à evolução histórica da universidade.

Bernheim e Chauí (2008) apresentam importantes reflexões acerca dos desafios da universidade na sociedade do conhecimento, em artigo produzido pelo Comitê Científico Regional para a América Latina e o Caribe, do Fórum da Unesco, realizado em Paris no ano de 2003. Apesar do evento ter ocorrido há mais de 10 anos (posterior à criação da Uergs), a leitura do texto e as conclusões dali retiradas são de extrema atualidade, tendo em vista que o texto procura indicar caminhos de longo prazo para as universidades, no contexto do paradigma da Sociedade do Conhecimento. Um primeiro aspecto a discutir é a questão da relação entre a universidade e a sociedade, Segundo os autores, "nem a universidade enclausurada, de costas para a sociedade, nem a universidade militante, invadida pelos ruídos e o clamor das ruas, mas sim uma universidade participante, como José Medina Echavarría advogava há décadas" (BERNHEIN; CHAUI, 2008, p. 17). Brunner (2014), a partir de uma abordagem mais crítica, infere também sobre a relação entre os sistemas nacionais de educação através principalmente das universidades e os estados nacionais, afirmando que "os sistemas nacionais de educação superior não são mais voltados exclusivamente aos estados nacionais, nem mesmo à comunidade nacional como uma esfera pública de representação cultural, mas aos mercados e às diferentes partes interessadas que constituem a sociedade civil, cujas demandas e interesses devem, agora, ser atendidos pelas universidades" (p. 16).

O Estado, ao perder sua "aura moral e altruísmo universal hegeliano" acaba perdendo também sua centralidade como referência cultural da nação. Além disso, acaba também por adquirir uma visão instrumental da universidade, com vistas a capacitar capital humano e incrementar a competitividade da economia nacional. $\mathrm{O}$ autor entende que a universidade contemporânea deve ter um alto grau de "autorreflexão e deliberação sobre suas práticas, em condições de atuar com autonomia acadêmica e de inovar no seu trabalho de criação, transmissão e aplicação do conhecimento"(p. 24). Voltando mais especificamente à relação da universidade com a sociedade e a busca de indicadores de qualidades para a gestão acadêmica, é necessário tratarmos das expectativas nutridas pela sociedade com relação ao papel que a universidade exercerá. No contexto da complexidade da ação de uma universidade nos seus diferentes papéis, Canterle e Favaretto (2008) se questionam a respeito dos "requisitos que podem orientar um modelo de gestão de forma a garantir a melhoria da qualidade nas instituições universitárias" (p. 395). Os autores propõem 4 princípios: (i) estabelecimento da missão, visão e os resultados levando em conta expectativa dos stakeholders presentes na sociedade; (ii) os objetivos e estratégias devem dar suporte à visão e à missão; (iii) os processos e os sistemas determinam a qualidade dos resultados; (iv) melhoria contínua deve ser garantida com avaliação contínua. Bernheim e Chauí (2008) abor- 
dam o conceito de relevância social, que enfatiza a relação dialética que deve existir entre sociedade e educação superior. Neste contexto, deve haver: (i) a mediação entre o que a sociedade espera e o que a universidade faz; (ii) maior articulação com o mundo do trabalho e com os problemas da sociedade; (iii) deve ser reforçado o papel da universidade como prestadora de serviços para a sociedade, orientada a "erradicar a pobreza, a intolerância, a violência, o analfabetismo, a fome, a doença e a degradação ambiental" (p. 21); (iv) a universidade deve contribuir para o fortalecimento do sistema educacional como um todo; (v) a educação superior deve visar "à criação de uma nova sociedade, nãoviolenta e não-exploradora, formada por indivíduos altamente esclarecidos, motivados e integrados, inspirados pelo amor à humanidade e guiados pela soberania"'(p. 21)

\section{INSTITUIÇÃO DO GRUPO DE TRABALHO E METODOLOGIA UTILIZADA}

O objetivo precípuo desta seção é descrever o processo instituído para repensar os rumos da Universidade Estadual do Rio Grande do Sul, a partir dos referenciais metodológicos adotados na constituição e no funcionamento do Grupo de Trabalho referido nas seções 2 e 3 .

$\mathrm{O}$ conceito que norteou os trabalhos foi a ideia da universidade participante (BERNHEIM; CHAUÍ, 2008), citada na seção anterior. Por isso a participação de diferentes representantes da comunidade acadêmica, do Governo, e uma constante articulação com o Conselho Superior da Universidade, que conta com representantes da sociedade. A representação da sociedade também esteve presente no GT a partir da SEPLAG, secretaria responsável pela articulação com o Conselhos Regionais de Desenvolvimento (FUNDAÇÃO DE ECONOMIA E ESTATÍSTICA, [2015?]), instância essencialmente direcionada ao atendimento das demandas regionais e locais.

Inicialmente, é preciso considerar que método não é uma abstração. "Método é ato vivo, concreto, que se revela nas nossas ações, na nossa organização do trabalho investigativo, na maneira como olhamos as coisas do mundo" (GATTI, 2007, p. 43). Por isso, a metodologia precisava refletir a realidade sobre a qual um conjunto de atores estava disposto a incidir. Um dos desafios dessa realidade consistia no fato de que era necessário olhar para o passado, objetivando recuperar os princípios fundantes da universidade; para o presente, procurando avaliar a complexidade dos problemas em contraposição às potencialidades reais da Uergs; para o futuro, buscando dar respostas aos novos desafios de uma instituição pública comprometida com um projeto inclusivo de sociedade.

A universidade pública de qualquer esfera administrativa é de responsabilidade do Estado, cujo principal agente é o governo. Nesse sentido, coube ao executivo estadual a iniciativa de propor a criação do GT, por meio do Decreto $\mathrm{n}^{\circ}$ 50.172/13 (RIO GRANDE DO SUL, 2013). Este tipo de instrumento tem limites e possibilidades: de um lado, é mais restrito do que uma lei; de outro, é mais ágil e produz resultados objetivos. Assim, o decreto determinou um prazo de 45 (quarenta e cinco) dias para que o grupo produzisse um Plano de Ações Estratégicas emergenciais para a Uergs. É importante salientar que o GT foi constituído por agentes governamentais (Secretaria da Ciência, Inovação e Desenvolvimento Tecnológico, Gabinete do Governador, Coordenação da Assessoria Superior e Secretaria de Planejamento e Participação Cidadã - SEPLAG), pela reitoria da Uergs e por convidados ligados à universidade: representantes de associações de docentes e de servidores técnicos e de apoio administrativo; sindicatos dessas categorias; diretório central de estudantes. De acordo com Creswell (2007), as fronteiras em torno das quais é produzido um estudo "delimitam o escopo da indagação, limitam as práticas utilizadas e direcionam a importância do estudo proposto para diferentes públicos" ( $\mathrm{p}$. 17). Desse modo, embora estratégicas, as ações propostas tinham o propósito de permitir uma rápida intervenção inicial compatível com o projeto de longo prazo, representado pelo Plano de Desenvolvimento Institucional da Uergs em vigor.

A composição do GT, conforme já mencionado, envolveu vários atores interessados no fortalecimento da Uergs, porém, com diferentes papéis na sociedade. A visão de governo é, necessariamente, mais ampla, pois a educação é um dos componentes das políticas públicas. Além disto, o Estado deve articular a melhoria do sistema educacional como um todo (BERNHEIM; CHAUÍ, 2008). No caso da educação superior, o investimento é fruto de opção do ente federado, posto que a responsabilidade constitucional do estado é para com a educação básica. A instituição da universidade estadual ocorreu na gestão 1999-2002, que guarda afinidade programática com a gestão 2011-2014. Esse fato pode ter contribuído para dar credibilidade ao interesse do executivo em resgatar o patrimônio social representado pela Uergs. Porém, a maior credencial do governo consistiu na ampliação do diálogo social, que incluiu a criação de secretaria específica para esse fim. Ao mesmo tempo, outras iniciativas voltadas para o fortalecimento institucional, a valorização dos professores e técnicos e a democratização da universidade concorreram para o estabelecimento dessa interlocução. Da parte da universidade, o zelo pela autonomia não inviabilizou o interesse em manter diálogo com o poder público, encarregado da manutenção da instituição. Por fim, docentes, técnicos administrativos e estudantes, cujas representações exigem compartilhamento de posições com seus pares, vislumbraram espaço e condições para apresentar seus pontos de destaque.

A complexidade do trabalho - associada ao prazo previsto pelo decreto que instituiu o GT - exigiu a escolha de uma dinâmica adequada. Desse modo, foram instituídos três subgrupos para atuarem de acordo com diretrizes construídas por todos os envolvidos no processo. A participação do conjunto do grupo na definição das diretrizes levou em consideração a recomendação de Gil (2007):

A dialética fornece as bases para uma interpretação 
dinâmica e totalizante da realidade, já que estabelece que os fatos sociais não podem ser entendidos quando considerados isoladamente, abstraídos de suas influências políticas, econômicas culturais etc. Por outro lado, como a dialética privilegia as mudanças qualitativas, opõe-se naturalmente a qualquer modo de pensar em que a ordem quantitativa se torne norma. (p.32)

A Diretriz $n^{\circ} 1$ consistia em repensar os cursos existentes e propor novos cursos para atender demandas, dialogando com as instituições públicas federais e comunitárias. Decorrida pouco mais de uma década da criação da Uergs, esta não deveria ser uma questão tão relevante a ponto de merecer uma revisão geral. Contudo, a sistemática falta de investimento somada à dispersão geográfica da instituição acabou por gerar situações preocupantes, como Unidades com um ou dois cursos e dois professores; manutenção de cursos incompatíveis com a realidade da região, visando, simplesmente, a sobrevivência da Unidade; impossibilidade de realização de pesquisa e de atividades de extensão, mesmo com corpo docente qualificado e apto para tais tarefas.

A Diretriz $\mathrm{n}^{\circ} 2$ propunha repensar os campi e as Unidades físicas, otimizando estruturas, espaços, territórios e atender a demanda mediante parcerias com instituições públicas federais e comunitárias. As observações feitas em relação aos cursos também são válidas para a estrutura organizacional e física. Registre-se, porém, que a preocupação do subgrupo não era, simplesmente, com os números, pois as investigações fundamentadas no método dialético distinguem-se da "ótica positivista, que enfatiza os procedimentos quantitativos" (GIL, 2007, p.32). Aliás, a opção da Uergs pela regionalização visou garantir acesso à educação superior pública à juventude de todas as regiões, mesmo que isso representasse significativa elevação de custos. Essa realidade mudou, significativamente, com a política de expansão de universidades e de institutos federais de educação, bem como pela ampliação da capilaridade das universidades comunitárias.

A Diretriz $\mathrm{n}^{\circ} 3$ afirmava a necessidade de implantar uma sede central da Uergs. Até a decisão de formar o GT, a reitoria, a biblioteca central, a Unidade de Porto Alegre (capital do estado) e outras estruturas de apoio funcionavam separadamente, em imóveis locados. Além de problemas técnicos e operacionais, essa situação dificultava a vivência acadêmica e a construção de referências simbólicas da única universidade estadual do Rio Grande do Sul.

O funcionamento dos subgrupos exigiu troca de informações constantes, formais e informais, facilitadas pela periodicidade de encontros e de reuniões. Não se pense, porém, que o diálogo esteve imune a tensões, contradições, avanços e recuos. De acordo com Kuenzer (2008), durante o transcurso da investigação, o pensamento deve mover-se entre "polos dialeticamente relacionados, buscando compreender onde e como se incluem/excluem, desaparecem ou originam uma nova realidade [...] captando a riqueza do movimento e da complexidade do real, com suas múltiplas determinações e manifestações" (p.65). De fato, é pela contradição que se chega a outra categoria do método dialético, a mediação, pela qual é possível produzir uma nova totalidade; no caso, novas formulações para as ações estratégicas da universidade. O GT não submeteu nenhuma divergência a voto e registrou as diversas posições em ata, como forma de acumular conteúdos, priorizando o processo de concertação sobre eventuais - e legítimos dissensos.

Houve, no mês de abril de 2013, quando o GT já havia elaborado algumas alternativas para a universidade, a apresentação dos trabalhos no II Encontro Estadual de Professores, Funcionários e Estudantes da Uergs (ASSOCIAÇÃO DOS SERVIDORES TÉCNICOS E DE APOIO ADMINISTRATIVO DA UERGS, 2015). $O$ evento foi realizado na Assembleia Legislativa do Estado do Rio Grande do Sul, e contou com uma expressiva participação da Comunidade Acadêmica. Foi um importante momento para o exercício da democracia na relação entre o Governo e a Universidade, especialmente no sentido de ser preservar a autonomia da universidade dos desafios da universidade na Sociedade do Conhecimento, que serão descritos na seção seguinte.

\section{AÇÕES IMPLEMENTADAS E PERSPECTIVAS FUTURAS}

O trabalho de todos os subgrupos foi orientado pelo Decreto $\mathrm{n}^{\circ}$ 50.172/13 (RIO GRANDE DO SUL, 2013), antes referido, que estabeleceu a competência e o escopo da produção do GT:

[...]Art. $2^{\circ}$ - Compete ao Grupo de Trabalho avaliar, discutir e apresentar sugestões sobre:

I - as necessidades dos diversos Campi da Universidade e a situação dos mesmos em termos de infraestrutura física e de aprimoramento de gestão;

II - o papel da Uergs no atendimento das necessidades da comunidade onde estão instalados os diversos Campi, que deverão atuar como instrumento para o desenvolvimento regional;

III - os desdobramentos futuros do Plano de Desenvolvimento Institucional em vigor, mediante definição de metas e prazos a serem considerados no Plano Estratégico da Uergs.

Como se observa, o art. $2^{\circ}$ propõe um diagnóstico da situação da instituição por regiões, ou seja, reafirma o papel da universidade como ferramenta para o desenvolvimento regional. Ao mesmo tempo, confere um sentido de globalidade ao articular os resultados do GT com os instrumentos de planejamento e gestão da própria Uergs. De fato, a necessidade de pensar de forma mais abrangente foi logo constatada nos trabalhos dos subgrupos. Isso levou a um processo de reorganização dos subgrupos 1 e 2 , pois o debate sobre cursos não podia estar desvinculado da realidade de cada região e, evidentemente, de todo o território.

É importante destacar que durante a vigência do decreto e de seu trabalho interno outras interlocuções foram necessárias, especialmente no sentido de dissipar dúvidas e evitar que as pressões pela manutenção do status quo inviabilizassem a proposta de fortalecimento da Uergs. Merecem registro: a preocupação de prefeitos 
e de movimentos sociais atuantes em regiões onde as unidades ou campi estavam em situação mais fragilizada; e o impacto do GT perante a Assembleia Legislativa, espaço natural de disputa de projeto político. Destaque-se, igualmente, a delicadeza da posição dos representantes da universidade, cujo papel era o de contribuir para a efetividade do trabalho coletivo sem, contudo, poder furtar-se das demandas corporativas. Após estabelecidas as diretrizes principais, a seguir elencadas, foi elaborado um documento, intitulado "Mensagem do Governo do Estado à Universidade Estadual do Rio Grande do Sul: Pacto pela Uergs" (RIO GRANDE DO SUL, [2013?]), que foi submetido ao Conselho Superior da Uergs, para apreciação e deliberação. O documento foi aprovado na íntegra, com pequenas observações e inclusões.

Como resultado, os subgrupos 1 e 2 apresentaram dez propostas:

$1^{\text {a) }}$ reagrupamento das Unidades da Uergs com o fortalecimento de um núcleo regional e capilaridade no território;

$2^{\text {a }) ~ b u s c a ~ d e ~ p a r c e r i a s ~ c o m ~ i n s t i t u i c ̧ o ̃ e s ~ p u ́ b l i c a s ~ d o ~ R S ~}$ (ex: Na cidade de Erechim, a Uergs mantém cursos superiores de Tecnologia em Gestão Ambiental e de Tecnologia em Fruticultura com escassas matrículas; instituída anos depois, a Universidade Federal da Fronteira Sul oferece cursos de Agronomia e de Engenharia Ambiental);

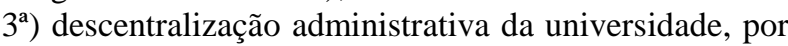
meio de autonomia de gestão administrativa e orçamentária;

$4^{a}$ ) transferência da biblioteca central da Uergs condicionada à transferência da Unidade de Porto Alegre;

$5^{\mathrm{a}}$ ) deslocamento da reitoria para o Centro de Treinamento da Companhia Estadual de Energia Elétrica CEEE (a ser, posteriormente, descrito);

$6^{\mathrm{a}}$ ) viabilização de aumentos orçamentários vinculados à nova estrutura, até que sejam alcançados os $0,5 \%$ previstos em lei;

$7^{a}$ ) cursos a serem priorizados: a) cursos vinculados ao fortalecimento de áreas estratégicas para o estado: energias renováveis; meio ambiente; tecnologias da informação - TI; metal mecânica e oceânica; b) gestão pública; c) educação; d) formação continuada;

$8^{\mathrm{a}}$ ) reposição automática de funcionários (ou seja, não depender de autorização do executivo para o preenchimento de vagas já existentes);

$9^{a}$ ) criação de um Conselho Comunitário, cuja representação teria assento no Conselho Universitário - Consun;

$10^{\mathrm{a}}$ ) criação do "Reuni Farroupilha", programa de indução do orçamento para cursos e regiões estratégicas para o estado.

Embora não estejam hierarquizadas, as propostas expressam preocupações conceituais, de visão do papel da universidade no contexto do desenvolvimento do estado e de procedimentos para viabilizar um redesenho da Uergs, mantendo seus compromissos originários e projetando o futuro. Nessa perspectiva, uma das reflexões reiteradas foi com a relação da universidade com o mundo do trabalho, aspecto fundamental do processo de desenvolvimento. Procurou-se evitar as simplificações que remetem a uma visão utilitária da educação. Como reflete Frigotto (2012), é necessário compreender que "a polissemia da categoria trabalho não é apenas e, sobretudo, semântica, teórica e epistemológica, ainda que mediada por essas dimensões, mas de natureza histórico-social, ontológica e ético-política" (p. 83).

O subgrupo 3 encarregou-se da implantação de uma sede central da Uergs, pois a realidade física e material da instituição eram incompatíveis com as exigências do ensino, pesquisa e extensão. De certo modo compreensível à época de sua criação, a manutenção da universidade em locais adaptados não contribuiu para o fortalecimento da imagem da instituição. No período da instituição do GT, a CEEE emprestava uma sala, no centro da cidade de Porto Alegre, próxima à reitoria, para o funcionamento da biblioteca central. A necessidade de retomar o imóvel fez com a Companhia oferecesse um espaço em seu Centro de Treinamento para o acervo da Uergs. Esse centro já contava com 14 (quatorze) edificações, perfeitamente adequadas às finalidades formativas da CEEE e compatíveis com um campi para a Uergs.

Resumidamente, o que seria, simplesmente, o empréstimo de um espaço para a biblioteca central transformou-se em uma complexa negociação com vistas à ocupação da área pela reitoria, biblioteca central e Unidade de Porto Alegre.

As diretrizes listadas acima foram submetidas ao CONSUN e aprovadas quase em sua maioria, antes de serem levemente modificadas em função de algumas particularidades regionais da instituição, em especial na região norte do Estado. Praticamente todas as pequenas alterações ocorreram no âmbito primeira estratégia, relativa ao reagrupamento das unidades da universidade. Tal aprovação praticamente integral destas medidas evidenciam o sucesso da estratégia de diálogo e concertação proposta.

Os cursos de pós-graduação strito sensu estão no horizonte da instituição desde sua criação. Agora, porém, se transformaram em um imperativo, em função de novas exigências para a educação superior. Caso não sejam oferecidos cursos de mestrado e de doutorado, até 2017, a Uergs perderá o estatuto de universidade. Assim, será importante que as áreas de oferta de mestrado e de doutorado guardem conexão com cursos de graduação já identificados com as prioridades da Uergs diante de seu papel no contexto do estado.

Outro desafio consiste na continuidade da recuperação financeira iniciada nos últimos quatro anos. Embora o Rio Grande do Sul tenha optado pela destinação de $35 \%$ dos recursos vinculados à educação na sua Constituição Estadual - CE, esse montante não tem sido, historicamente, investido na educação básica. Antes, porém, de discutir a destinação de parte desse percentual para a educação superior, o parlamento optou por alterar a CE para determinar, no art. $201 \S 3 .^{\circ} \mathrm{O}$ Estado 
aplicará $0,5 \%$ (meio por cento) da receita líquida de impostos próprios na manutenção e desenvolvimento do ensino superior público e, através de crédito educativo e de bolsa de estudos, integral ou parcial, no ensino superior comunitário, cabendo à lei complementar regular a alocação e fiscalização deste recurso. [Redação dada pela Emenda Constitucional n. ${ }^{\circ}$ 66, de 19/12/12]. (RIO GRANDE DO SUL, 2012)

Observe-se que o texto constitucional não torna a universidade estadual destinatária exclusiva dos recursos, pois abre a possibilidade de financiamento de crédito educativo e de bolsas de estudos para o ensino comunitário. A destinação de verbas públicas, exclusivamente, para a educação pública foi uma tese defendida pelo movimento social no final dos anos 1980, no contexto da formulação da nova Constituição Federal e da Lei de Diretrizes e Bases da Educação Nacional - LDB (que só seria aprovada, com outro texto e em outra conjuntura, em 1996). A proposta não teve viabilidade política no parlamento brasileiro. Da Assembleia Legislativa do RS também não se esperava outra reação, tendo em vista a polêmica que envolve a temática. No caso do estado gaúcho, é importante mencionar que as instituições comunitárias se credenciaram em diversas regiões, em espaços não ocupados por universidades públicas, que só começaram a expandir-se em meados dos anos 2000 . Por isso, o ponto central do debate sobre financiamento a Uergs, de certo modo, continua em aberto, não obstante o avanço representado pela regulamentação constitucional.

Outro ponto relevante diz respeito à democratização da universidade, Durante a vigência do GT sempre esteve presente a questão da autonomia da universidade versus sua relação com o governo, a quem compete, em última instância, a responsabilidade pelo financiamento e o compromisso político com seu fortalecimento. Portanto, o tema da democratização entrou de forma tangencial, como componente do debate sobre o papel do Consun na legitimação - ou não - das propostas produzidas pelo GT. O Conselho Universitário é a instância deliberativa da universidade e nele têm assento, além dos 27(vinte e sete) representantes da comunidade acadêmica, 3 (três) governamentais. A sugestão do GT foi a introdução de um debate sobre a instituição de um Conselho Comunitário, a exemplo do que existe na Universidade de Brasília - UnB e outras com a finalidade de ampliar o debate da universidade com a sociedade. Afinal, é ela a destinatária das políticas educacionais. Abrir-se aos atores interessados ou, mesmo, provocar seu interesse, acaba fortalecendo a própria instituição em sua capacidade de incidência sobre a realidade e sua contribuição para a transformação social.

\section{CONSIDERAÇÕES FINAIS}

A instituição de um Grupo de Trabalho para abordar qualquer temática só tem importância se for reveladora da disposição de seus proponentes no sentido de encaminhar as questões que lhe foram propostas. Neste caso, o GT não foi uma tarefa entregue a um grupo de expertos que deveriam produzir as melhores soluções técnicas ou brilhantes teorias. Por óbvio, a maior parte dos envolvidos dominava a temática, mas o critério de composição levou em conta, em primeiro lugar, o nível de comprometimento de cada participante - pela representação que lhe foi atribuída - para com o futuro da Universidade Estadual do Rio Grande do Sul.

Os dois primeiros anos de governo mostraram que os investimentos financeiros feitos na universidade, mesmo substancialmente aumentados, não alteravam o quadro de perda de condições da universidade em cumprir com as finalidades para as quais foi criada. Concursos para professores e funcionários deram fôlego à gestão, mas não evitaram o esvaziamento de cursos que, há anos, vinham funcionando precariamente, e cujos alunos temiam não conseguir se formar. A conquista do plano de carreira deu dignidade salarial aos profissionais, porém, não as condições para realizar pesquisa ou participar de atividades de extensão, tendo em vista o reduzido número de docentes em algumas Unidades. Diante de uma situação em que a sobrevivência da universidade estava mais dependente da aguerrida disposição de profissionais e de equipes de trabalho do que de condições objetivas de funcionamento, impunha-se uma escolha: deixar que a Uergs continuasse como estava ou superar vários obstáculos para fortalecê-la?

A decisão de governo foi pelo fortalecimento a Uergs, pois, mesmo com o aumento de vagas públicas no estado - pela ação do governo federal - a universidade estadual mantinha sua vocação de fomentadora do projeto de desenvolvimento do estado por meio da inclusão de setores da juventude não alcançados por outras instituições. Como fazer isso? A formação do GT foi uma decisão sobre o conteúdo e sobre o método, pois nada iria progredir se não houvesse um intenso diálogo pressionado por prazos e resultados. Em resumo, a iniciativa só teria sucesso se todos os atores se sentissem participantes e, ao mesmo tempo, soubessem que não lhes seriam transferidas responsabilidades e ônus políticos que correspondiam ao governo. As propostas seriam fruto da concertação - onde todos fazem concessões - mas não se estabelece nenhuma relação de subordinação entre as partes envolvidas.

O futuro a Uergs continuará associado ao projeto de desenvolvimento com inclusão, o que significa que não há neutralidade possível. "Do ponto de vista político, Estado e organização da sociedade não são duas coisas distintas. O Estado é a organização da sociedade" (MARX; ENGELS, 2010, p.38, grifos dos autores). O conceito gramsciano de hegemonia avança nessa construção, mostrando que a sociedade interage, exerce um papel importante na implementação - ou não - de políticas públicas. Por isso, caberá à universidade exercer esse papel na determinação de seu futuro em realidades distintas do ponto de vista da gestão do estado do RS.

\section{REFERENCIAS \\ ASSOCIAÇÃO DOS SERVIDORES TÉCNICOS E DE APOIO ADMINISTRATIVO DA UERGS. Disponível em: http://assuergs-}


uergs.blogspot.com.br/2013/04/convite-2-encontroestadual-de.html. Acesso em: 26 jan, 2015.

BERNHEIM, C. T; CHAUÍ, M.S. Desafios da universidade na sociedade do conhecimento: cinco anos depois da conferência mundial sobre educação superior. Brasília: UNESCO, 2008. 44 p.

BRASIL. Ministério da Educação. Instituições de curso superior e cursos cadastrado. 2015. Disponível em: http://emec.mec.gov.br. Acesso em: 20 jan. 2015.

BRUNNER, J. J. A ideia da universidade pública: narrações contrastantes. Ensaio: aval. pol. públ. Educ., Rio de Janeiro, v.22, n. 82, p. 11-30, jan./mar. 2014

CANTERLE, N. M. G.; FAVARETTO, F. Proposta de um modelo referencial de gestão de indicadores de qualidade na instituição universitária. Ensaio: aval. pol. públ. Educ., Rio de Janeiro, v. 16, n. 60, p. 393-412, jul./set. 2008

CRESWELL, J. W. Projeto de Pesquisa: métodos qualitativos, quantitativo e misto. 2. ed. Porto Alegre: Artmed, 2007.

FRIGOTTO, G. A Polissemia da Categoria Trabalho e a Batalha das Ideias nas Sociedades de Classe. In: CIAVATTA, Maria (Org.). Gaudêncio Frigotto: um intelectual crítico nos pequenos e grandes embates. Belo Horizonte: Autêntica, 2012.

FUNDAÇÃO DE ECONOMIA E ESTATÍSTICA.

COREDES: Conselhos Regionais de Desenvolvimento. [2015?]. Disponível em: < http://www.fee.rs.gov.br/perfilsocioeconomico/coredes/>. Acesso em: 26 jan. 2015.

GATTI, B. A. A Construção da Pesquisa em Educação no Brasil. Brasília: Líber Livro, 2007.

GIL, A. C. Métodos e Técnicas de Pesquisa Social. 5 ed. São Paulo: Atlas, 2007.

INSTITUTO NACIONAL DE ESTUDOS E PESQUISAS EDUCACIONAIS ANÍSIO TEIXEIRA. Censo da Educação Superior de 2003: Resumo Técnico. Brasília: Inep, 2004. Disponível em: < http://download.inep.gov.br/download/superior/censo/2 004/resumo_tecnico_050105.pdf. > Acesso em: 19 jan. 2015.
INSTITUTO NACIONAL DE ESTUDOS E PESQUISAS EDUCACIONAIS ANÍSIO TEIXEIRA. Censo da Educação Superior de 2010: Resumo Técnico. Brasília: Inep, 2011. Disponível em:

<http://download.inep.gov.br/download/superior/censo/ 2010/resumo_tecnico_censo_educacao_superior_2010.p df>. Acesso em: 19 jan. 2015.

KUENZER, A. Z. Desafios Teórico-metodológicos da Relação Trabalho-Educação e o Papel Social da Escola. In: FRIGOTTO, Gaudêncio (Org.). Educação e Crise do Trabalho: perspectivas de final de século. Petrópolis: Vozes, 2008.

MARX, K.; ENGELS, F. Lutas de Classes na Alemanha. 1 ed. São Paulo: Boitempo, 2010.

RIO GRANDE DO SUL. Mensagem do governo do estado à Universidade Estadual do Rio Grande do Sul: pacto pela Uergs. [2013?]. Disponível em: < http://www.sinprors.org.br/arquivos/1_8_2013_uergs__mensagemdo_gove.pdf $>$. Acesso em: 26 jan 2015.

. Lei n. 11.646, de 10 de julho de 2001. Autoriza o Poder Executivo a criar a Universidade Estadual do Rio Grande do Sul - UERGS e dá outras providências. 2001. Disponível em: <

<http://www.uergs.edu.br/uploads/legislacao/11570355 12Lei_de_Criacao_da_UERGS_11646_01.pdf $>$, Acesso em: 19 jan. 2015.

\section{Constituição do Estado do Rio Grande do}

Sul. 1989. Disponível em:

<http://www2.al.rs.gov.br/dal/LinkClick.aspx?fileticket $=\mathrm{dqD} 9 \mathrm{RmsBuJs} \% 3 \mathrm{~d} \&$ tabid $=3683 \& \mathrm{mid}=5359>$. Consulta em: 24 jan. 2015.

Decreto $n^{\circ}$ 50.172, de 20 de março de 2013. Institui Grupo de Trabalho com a finalidade de elaborar Plano de Ações Estratégicas emergenciais para a Universidade Estadual do Rio Grande do Sul - UERGS. 2013.

UNIVERSIDADE ESTADUAL DO RIO GRANDE DO SUL. Plano desenvolvimento institucional: PDI 2012-2016. Porto Alegre: Uergs, 2012. 